\title{
A critical evaluation of the role of subcutaneous abatacept in the treatment of rheumatoid arthritis: patient considerations
}

This article was published in the following Dove Press journal:

Biologics:Targets and Therapy

17 February 2014

Number of times this article has been viewed

\author{
Alvin F Wells ${ }^{1,2}$ \\ Nicole Jodat' \\ Michael Schiff ${ }^{3}$ \\ 'Rheumatology and Immunotherapy \\ Center, Franklin, WI, USA; ${ }^{2}$ Duke \\ University Medical Center, Durham, \\ NC, USA; ${ }^{3}$ University of Colorado, \\ School of Medicine, Denver, CO, USA
}

\begin{abstract}
There are now more therapeutic options for the treatment of rheumatoid arthritis (RA) than ever before, involving a range of mechanisms of action and different routes of administration. The T-cell costimulation modulator abatacept is the first biologic therapy for RA to be available in both subcutaneous (SC) and intravenous (IV) formulations. This review evaluates the utility of SC abatacept, with a particular focus on patient-reported outcomes, including physical function, pain, fatigue, and quality of life. Practical questions relating to the clinical use of SC abatacept are also addressed, including the relevance of abatacept's mechanism of action; whether IV and SC abatacept are comparable; if patients can easily switch from IV to SC abatacept; whether an IV loading dose is needed; and if temporary treatment interruptions or lack of concomitant methotrexate can affect efficacy or safety. Topics that are of particular concern to patients when using SC biologics, such as injection-site reactions, are also discussed. Observational data from registries and meta-analyses of clinical studies suggest comparable clinical efficacy between biologic disease-modifying antirheumatic drugs; however, such analyses rarely focus on key determinants of patient quality of life such as pain, fatigue, and physical function. The head-to-head AMPLE study is one of the first studies powered to directly compare two biologics in patients with RA. Patient-reported outcomes from year 1 of the ongoing study are evaluated, demonstrating comparable improvements in physical function, pain, fatigue, Short Form-36 Health Survey, and Routine Assessment of Patient Index Data 3 scores between SC abatacept and SC adalimumab when administered with concomitant methotrexate. In summary, the data presented herein show that the SC formulation of abatacept provides a valuable addition to the range of available therapy options for patients with RA, capable of significantly improving key patient considerations such as pain, disability, loss of function, fatigue, and quality of life.
\end{abstract}

Keywords: rheumatoid arthritis, abatacept, subcutaneous, biologic DMARD, patient-reported outcomes

\section{Introduction}

Rheumatoid arthritis (RA) is a chronic autoimmune disease characterized by inflammation of synovial joints. RA occurs in approximately twice as many women as men, ${ }^{1}$ and often begins at a young age. Without aggressive control of the inflammatory process, the disease may lead to damage of not only the cartilage and bone but also the surrounding connective tissues. ${ }^{2}$ The disease is systemic in nature and may cause damage to other organs in addition to the joints. Importantly, RA is associated with pain, fatigue, disability, and functional loss, which can substantially impact a patient's health-related quality of life (HRQoL). ${ }^{3,4}$
Correspondence: Alvin F Wells Rheumatology and Immunotherapy Center, 4225 West Oakwood Park Court, Franklin, WI 53I54, USA

$\mathrm{Tel}+\mathrm{I} 4 \mid 44350025$

Fax +I 4I4 4350026

Email a.f.wells@att.net 
Patient-reported outcomes (PROs) that measure patient-assessed health, quality of life, and treatment response are particularly important in cases in which clinical outcomes do not result in perceptible benefits to the patient. ${ }^{5}$ However, treatment outcomes may not always be equally apparent to both patient and clinician. ${ }^{5}$

Abatacept is a T-cell costimulation modulator that has demonstrated efficacy in a range of patients with RA, including those with early RA who are naïve to treatment with methotrexate (MTX), ${ }^{6}$ those who have demonstrated an inadequate response to treatment with MTX or other nonbiologic disease-modifying antirheumatic drugs (DMARDs), ${ }^{7-11}$ and those who have failed prior treatment with anti-tumor necrosis factor (TNF) antagonists. ${ }^{12,13}$

Until recently, abatacept had been available only as an intravenous (IV) formulation, administered every 4 weeks according to a weight-tiered dosing regimen $(\sim 10 \mathrm{mg} / \mathrm{kg})$. A subcutaneous (SC) formulation of abatacept is now approved for the treatment of RA in the US and EU, using a weekly, fixed-dose regimen of $125 \mathrm{mg}$. Abatacept is the first biologic therapy for RA that is available in both SC and IV formulations. The availability of these alternative formulations of abatacept provides additional therapeutic options and flexibility for patients with RA, with many patients likely to benefit from the ease of use and convenience of self-administered SC injections.

This review will provide an evaluation of the SC formulation of abatacept, with particular focus on patient considerations. In that regard, a number of practical clinical questions will be addressed. Namely:

1. What is the relevance of the mechanism of action of an antirheumatic drug and how is abatacept unique?

2. Do the SC and IV formulations of abatacept have comparable efficacy and safety?

3. How effective are SC and IV abatacept in improving PROs?

4. Can patients switch from IV to SC abatacept with maintained efficacy and without increased safety concerns?

5. If a patient is treated with the $\mathrm{SC}$ formulation of abatacept, does the patient first need an IV abatacept loading dose?

6. Can patients interrupt treatment with SC abatacept without loss of long-term efficacy and without increased safety concerns upon reinitiation?

7. Can patients receive SC abatacept as monotherapy without the loss of efficacy and without increased safety concerns?

8. Does SC abatacept have comparable efficacy, safety, and tolerability to other biologic DMARDs?
9. How important is a biologic's route of administration to patients with RA?

By addressing these questions, we hope to evaluate how SC abatacept can improve patients' quality of life as well as provide a practical guide for the use of SC abatacept in the clinic.

\section{What is the relevance of the mechanism of action of an antirheumatic drug and how is abatacept unique?}

A variety of biologic agents are now available for the treatment of RA. The different mechanisms of action demonstrated by these biologics may result in different clinical effects, depending on which cell types are being targeted. ${ }^{14}$ It has also been suggested that the mechanisms of action of some biologics may benefit particular patients more than others. For example, patients with high levels of inflammation may benefit from treatment with cytokine inhibitors, whereas patients with B-cell-driven RA may respond better to B-cell-directed agents. ${ }^{14}$

The CD28:CD80/86 interaction is a costimulation signal required for full T-cell activation, ${ }^{15}$ which in turn is involved in amplification of the inflammatory cascade that leads to joint inflammation. ${ }^{16}$ Abatacept is a fusion protein consisting of the extracellular domain of cytotoxic T-lymphocyte antigen 4 and a modified fragment of the Fc region of immunoglobulin G1. Abatacept has a higher affinity than CD28 for CD80:86 binding on the antigen-presenting cell, modulating its interaction with $\mathrm{CD} 28$ on the T-cell. ${ }^{15}$ By regulating the CD28:CD80/86 costimulatory signal, abatacept selectively modulates T-cell activation, working upstream in the immune response and impacting both $\mathrm{T}$ - and B-cells involved early in the RA disease process (Figure 1). ${ }^{15,17-25}$ Through the selective modulation of the CD28:CD80/86 costimulatory signal early in the RA disease process, abatacept has demonstrated the ability to regulate various cell types involved in mediating synovial inflammation and joint damage, which can lead to pain and disability. ${ }^{14}$

As a consequence, it is likely that abatacept's unique mechanism of action impacts various stages of RA disease pathology, improving symptoms that can considerably impact on patients' quality of life, such as pain and disability.

\section{Do the SC and IV formulations of abatacept have comparable efficacy and safety?}

The SC and IV formulations of abatacept have demonstrated comparable efficacy, with the Phase III ACQUIRE 


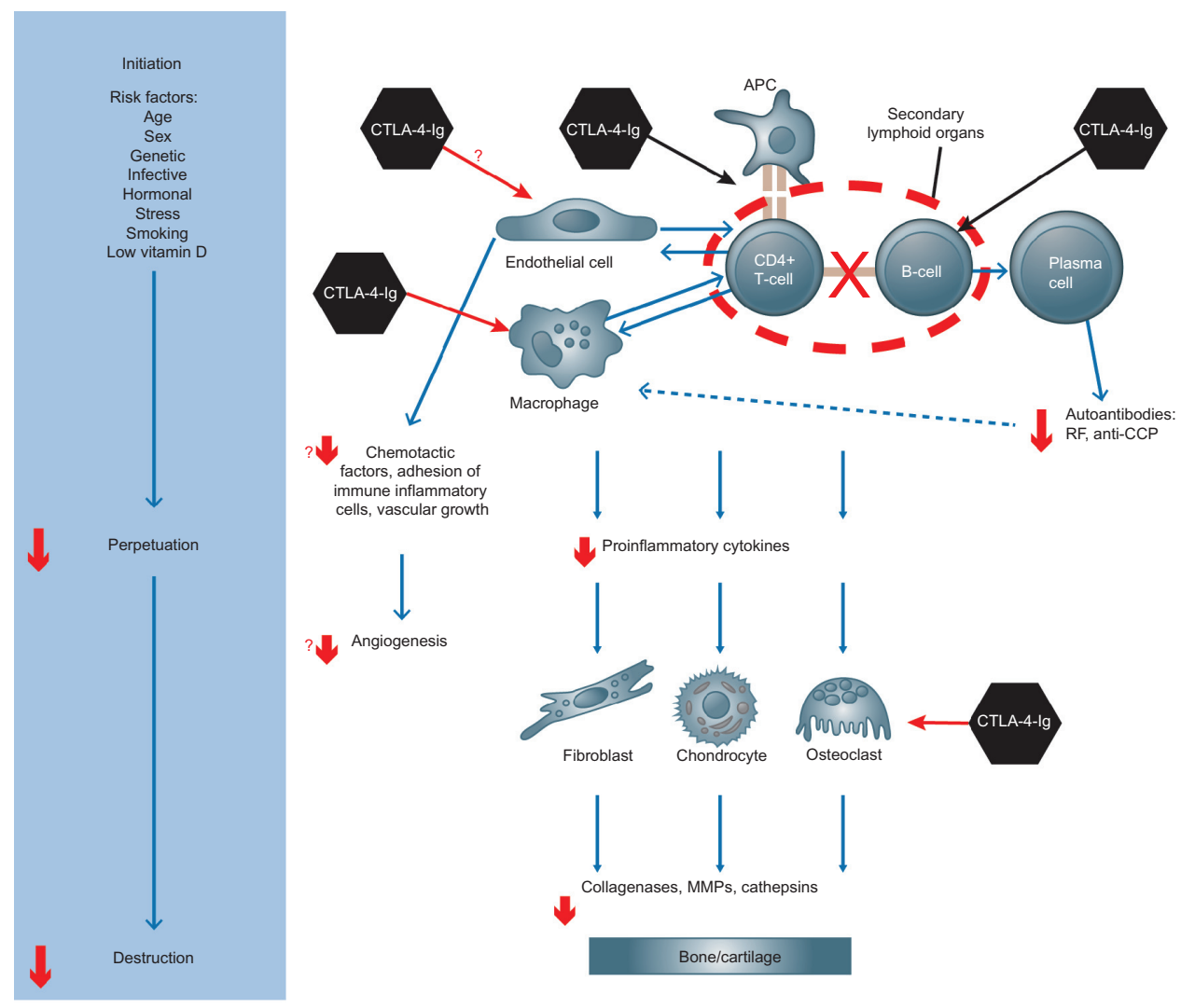

Figure I Schematic demonstrating the impact of abatacept (CTLA-Ig) on different cell types involved in the immune cascade.

Note: Reprinted from Autoimmunity Reviews, Volume 12/lssue 7, Maurizio Cutolo, Steven G Nadler, Advances in CTLA-4-Ig-mediated modulation of inflammatory cell and immune response activation in rheumatoid arthritis, 758-767, Copyright 2013, with permission from Elsevier. ${ }^{14}$

Abbreviations: Anti-CCP, anti-cyclic citrullinated protein; APC, antigen-presenting cell; CTLA-4-lg, cytotoxic T lymphocyte-associated antigen 4 immunoglobulin fusion protein; MMP, matrix metalloproteinase; RF, rheumatoid factor.

(Abatacept Comparison of Sub[QU]cutaneous versus Intravenous in inadequate Responders to methotrexatE) study (Table 1) meeting its primary end point by showing the noninferiority of the SC formulation compared with the IV formulation, as assessed by response according to the American College of Rheumatology (ACR) $20 \%$ improvement criteria (ACR20) after 6 months of treatment ${ }^{26} 76.0 \%$ of patients in the SC abatacept group and $75.8 \%$ of patients in the IV abatacept group achieved an ACR20 response at month 6 (per-protocol population; estimated difference between treatment groups: $0.3 \%$ [95\% confidence interval (CI): $-4.2 \%, 4.8 \%]) .{ }^{26}$

The long-term extension (LTE) period of the ACQUIRE study, during which all patients (including those originally randomized to IV abatacept) received open-label SC abatacept, demonstrated that ACR responses and the Disease Activity Score (DAS) assessed on 28 joints based on C-reactive protein (CRP) remission rates observed at month 6 in the $\mathrm{SC}$ and IV abatacept groups were maintained through month 32 and remained similar between the original treatment groups. ${ }^{27}$ These findings are consistent with those observed in the LTE periods of the Phase III studies of IV abatacept studies
Abatacept in Inadequate responders to Methotrexate (AIM) and Abatacept Trial in Treatment of Anti-TNF INadequate responders (ATTAIN), during which initial improvements in clinical efficacy were maintained with continued treatment for up to 5 years. ${ }^{28,29}$

The ACQUIRE study demonstrated comparable safety and tolerability for the SC and IV formulations of abatacept, with similar rates of adverse events ([AEs] 67.0\% vs [versus] $65.2 \%$ ), serious AEs ([SAEs] $4.2 \%$ vs $4.9 \%$ ), and discontinuations due to SAEs ( $1.1 \%$ vs $1.9 \%)$ over 6 months. Frequencies of events of special interest were also comparable, with serious infections $(\mathrm{n}=5[0.7 \%]$ vs $\mathrm{n}=10[1.4 \%])$, malignancies $(\mathrm{n}=3$ $[0.4 \%]$ vs $n=5[0.7 \%]$ ), and prespecified autoimmune events $(n=7[1.0 \%]$ vs $n=6[0.8 \%])$ reported in similar proportions of patients in the SC and IV abatacept groups. ${ }^{26}$

Although current safety data represent fewer patientyears of exposure for SC abatacept than for IV abatacept, comparisons of incidence rates ([IRs] expressed as events per 100 patient-years [95\% CI]) from an integrated safety analysis of five SC abatacept trials (one Phase II study and four Phase IIIb studies [Evaluation of Abatacept administered subcutaneousLy in aduLts with active rheumatOid arthritis: 
Table I Phase III clinical studies

\begin{tabular}{|c|c|c|c|c|c|}
\hline Study name & ALLOW $^{53}$ & ACQUIRE ${ }^{26}$ & ACCOMPANY 54 & ATTUNE ${ }^{47}$ & AMPLE $^{56}$ \\
\hline Study duration & 9 months & 6 months & 4 months & 12 months & 24 months \\
\hline Study design & $\begin{array}{l}\text { Double-blind, } \\
\text { randomized, } \\
\text { placebo-controlled }\end{array}$ & $\begin{array}{l}\text { Double-blind, } \\
\text { randomized, } \\
\text { placebo-controlled }\end{array}$ & $\begin{array}{l}\text { Open-label, } \\
\text { nonrandomized, } \\
\text { uncontrolled }\end{array}$ & $\begin{array}{l}\text { Open-label, } \\
\text { nonrandomized, } \\
\text { uncontrolled }\end{array}$ & $\begin{array}{l}\text { Single-blind, randomized, } \\
\text { uncontrolled }\end{array}$ \\
\hline $\begin{array}{l}\text { Patient } \\
\text { population }\end{array}$ & $\begin{array}{l}\text { Active RA, } \\
\text { inadequate responders } \\
\text { to MTX }\end{array}$ & $\begin{array}{l}\text { Active } R A \text {, } \\
\text { inadequate } \\
\text { responders to MTX }\end{array}$ & $\begin{array}{l}\text { Active } R A, I R \text { to } \geq 1 \\
\text { DMARD (MTX-naïve } \\
\text { or inadequate } \\
\text { responders to } M T X \text { ) }\end{array}$ & $\begin{array}{l}\text { Active } \mathrm{RA} \text {, inadequate } \\
\text { responders to MTX } \\
\text { or anti-TNF }\end{array}$ & $\begin{array}{l}\text { Active RA, inadequate } \\
\text { responders to MTX, } \\
\text { biologic-naïve }\end{array}$ \\
\hline Treatment & $\begin{array}{l}\text { SC abatacept }+ \text { MTX } \\
\text { (continuous vs } \\
\text { withdrawn/reintroduced) }\end{array}$ & $\begin{array}{l}\text { SC or IV abatacept + } \\
\text { MTX }\end{array}$ & $\begin{array}{l}\text { SC abatacept } \\
\text { (with/without MTX) }\end{array}$ & $\begin{array}{l}\text { SC abatacept }+ \\
\text { nonbiologic } \\
\text { DMARDs }\end{array}$ & $\begin{array}{l}\text { SC abatacept }+ \text { MTX or } \\
\text { SC adalimumab + MTX }\end{array}$ \\
\hline $\begin{array}{l}\text { Total number } \\
\text { of patients }\end{array}$ & 167 & $\mathrm{I}, 457$ & 100 & 123 & 646 \\
\hline $\begin{array}{l}\text { Primary end } \\
\text { point }\end{array}$ & $\begin{array}{l}\text { Immunogenicity rate } \\
\text { and safety at } 6 \text { months }\end{array}$ & $\begin{array}{l}\text { Noninferiority by } \\
\text { ACR20 response } \\
\text { rate at month } 6\end{array}$ & $\begin{array}{l}\text { Immunogenicity rate } \\
\text { at month } 4\end{array}$ & $\begin{array}{l}\text { Safety during the } \\
3 \text { months after } \\
\text { switching from long- } \\
\text { term IV abatacept }\end{array}$ & $\begin{array}{l}\text { Noninferiority by ACR20 } \\
\text { response rate at I year }\end{array}$ \\
\hline $\begin{array}{l}\text { PRO data } \\
\text { available }\end{array}$ & HAQ-DI & $\begin{array}{l}\text { HAQ-DI, patient's } \\
\text { assessment of disease } \\
\text { activity, patient- } \\
\text { assessed pain }\end{array}$ & HAQ-DI & HAQ-DI & $\begin{array}{l}\text { HAQ-DI, patient's } \\
\text { assessment of disease } \\
\text { activity, patient-assessed } \\
\text { pain, fatigue, SF-36, RAPID3 }\end{array}$ \\
\hline
\end{tabular}

Note: "Patients who completed $\geq 4$ years of treatment with IV abatacept in the AIM or ATTAIN trials.

Abbreviations: ACCOMPANY, AbataCept in SubjeCts with RheumatOid Arthritis AdMinistered Plus or Minus BAckground Methotrexate SubcutaNeousIY; ACQUIRE, Abatacept Comparison of Sub[QU]cutaneous versus Intravenous in inadequate Responders to methotrexatE; ACR20, American College of Rheumatology $20 \%$ improvement criteria; AIM, Abatacept in Inadequate responders to Methotrexate; ALLOW, Evaluation of Abatacept administered subcutaneousLy in aduLts with active rheumatOid arthritis: impact of Withdrawal and reintroduction on immunogenicity, efficacy and safety; AMPLE, Abatacept versus adaliMumab comParison in bioLogic-naïve RA subjects with background mEthotrexate; ATTAIN, Abatacept Trial in Treatment of Anti-TNF INadequate responders; ATTUNE, Abatacept in subjecTs who swiTch from intravenoUs to subcutaNeous thErapy; DMARD, disease-modifying antirheumatic drug; HAQ-DI, Health Assessment Questionnaire-Disability Index; IV, intravenous; MTX, methotrexate; PRO, patient-reported outcomes; RA, rheumatoid arthritis; RAPID3, Routine Assessment of Patient Index Data 3; SC, subcutaneous; SF-36, Short Form-36 Health Survey; TNF, tumor necrosis factor.

impact of Withdrawal and reintroduction on immunogenicity, efficacy and safety (ALLOW), ACQUIRE, AbataCept in SubjeCts with RheumatOid Arthritis AdMinistered Plus or Minus BAckground Methotrexate SubcutaNeouslY (ACCOMPANY), Abatacept in subjecTs who swiTch from intravenoUs to subcutaNeous thErapy (ATTUNE)]) (Table 1) ${ }^{30}$ with a similar integrated analysis of eight IV abatacept trials (three Phase II studies and five Phase III studies [AIM, ATTAIN, ASSURE (Abatacept Study of Safety in Use with other Rheumatoid arthritis thErapies), ATTEST (Abatacept or infliximab versus placebo, a Trial for Tolerability, Efficacy and Safety in Treating RA), ARRIVE (Abatacept Researched in Rheumatoid arthritis patients with an Inadequate anti-TNF response to Validate Effectiveness)]), ${ }^{31}$ suggest that $\mathrm{SC}$ and IV abatacept demonstrate similar long-term safety profiles. The SC integrated analysis comprised 1,879 patients, with 3,086 patient-years of exposure to SC abatacept, and a mean (range) exposure of 20 (2-56) months..$^{30,32}$ The IV integrated analysis comprised 4,149 patients, with 12,132 patient-years of exposure to IV abatacept, and a mean (range) exposure of 35.6 (1.9-104.2) months. ${ }^{31}$ The IRs $(95 \% \mathrm{CI})$ of infections and serious infections for $\mathrm{SC}$ abatacept from the integrated analysis were $53.91(50.69,57.33)$ and $1.94(1.50,2.50)$, compared with $75.68(73.00,78.44)$ and $2.87(2.57,3.19)$ for IV abatacept. ${ }^{30}$ The most frequent (IR $>0.10$ ) serious infections with SC abatacept were pneumonia $(0.36[0.20,0.65])$, urinary tract infection $(0.16[0.07,0.39])$, and gastroenteritis $(0.13[0.05,0.35]),{ }^{30,32}$ which are consistent with those reported for the IV formulation..$^{31}$ Pulmonary and peritoneal tuberculosis were each recorded in one SC abatacept-treated patient each (each $0.03[0.00,0.23]) .{ }^{30}$

The IR of autoimmune events was $1.28(0.93,1.75)$ in patients treated with SC abatacept, compared with 1.99 (1.74, 2.26) in IV abatacept-treated patients. ${ }^{30}$ The most frequent (IR $>0.10)$ autoimmune events were psoriasis $(0.29[0.15,0.56])$ and Sjögren's syndrome $(0.19[0.09,0.43]),{ }^{30,32}$ which are consistent with those reported for the IV abatacept formulation. ${ }^{31}$

The IR of malignancies (excluding nonmelanoma skin cancer) was $0.68(0.45,1.05)$ in patients treated with $\mathrm{SC}$ abatacept, compared with $0.73(0.58,0.89)$ in patients treated with IV abatacept. ${ }^{30}$ The most frequent (IR $>0.10$ ) malignancies in patients treated with SC abatacept were basal cell carcinoma (0.46 [0.27, 0.77]), breast cancer, and squamous cell carcinoma of the skin (each $0.16[0.07,0.39]) .{ }^{32}$ 
The IRs of serious infections, autoimmune events, and malignancies did not increase with increasing exposure to SC abatacept up to month $24 .{ }^{32}$

Seventeen deaths were reported in the SC abatacept integrated analysis, with an IR $(95 \% \mathrm{CI})$ of $0.55(0.34,0.89)$, which is comparable with the IR of deaths reported for IV abatacept $(0.60[0.47,0.76]){ }^{30}$

These findings suggest that patients and clinicians may choose to administer abatacept either via IV infusion or by (self-administered) SC injection, with comparable efficacy and safety observed for each formulation.

\section{How effective are SC and IV abatacept in improving PROs?}

Current treatment paradigms aim to lessen the impact of RA by reducing disability and improving patients' quality of life, in addition to reducing clinical disease activity. Clinicians often consider pain and loss of function, resulting from continuing synovitis and progressive joint damage, as the most important impacts of RA; $;^{33}$ however, patients with RA also identify fatigue as having a dominant influence over their quality of life. ${ }^{34,35}$

Clinical trial data for IV abatacept demonstrate clinically and statistically significant improvements in a range of PROs, compared with MTX and other nonbiologic DMARD treatments, including activity limitation, ${ }^{5,36,37}$ physical function, ${ }^{7,38,39}$ sleep quality, ${ }^{5,37,40}$ fatigue, ${ }^{5,37,38,41}$ and all domains of the Short Form-36 Health Survey (SF-36) survey (physical functioning, physical role, pain, general health, vitality, social functioning, emotional role, mental health, and the physical and mental component summaries). . $12,38,39,41,42$ In addition, improvements in these outcomes appear to be closely related to clinical response. . $^{36,41,42}$

The Phase III ACQUIRE study (Table 1) compared three PROs (physical function and patient's global assessments of disease activity and pain) in patients treated with SC or IV abatacept. Improvements in physical function were assessed by the proportion of patients achieving a Health Assessment Questionnaire-Disability Index (HAQ-DI) response (defined as an improvement of $\geq 0.3$ units from baseline). Comparable HAQ-DI response rates were observed for both formulations (SC and IV) of abatacept throughout the 6-month study. ${ }^{26}$ At month $6,68.2 \%$ (95\% CI: $64.8,71.6)$ of patients in the SC abatacept group and $63.8 \%$ (95\% CI: 60.3, 67.3) of patients in the IV abatacept group were HAQ-DI responders (estimated difference between treatment groups: $4.5 \%$ [95\% CI: -0.4, 9.4]) (Figure 2). ${ }^{26}$ The adjusted mean (standard error of the mean $[\mathrm{SEM}])$ change from baseline to month 6 in HAQ-DI score was $-0.69(0.02)$ and $-0.70(0.02)$ in the

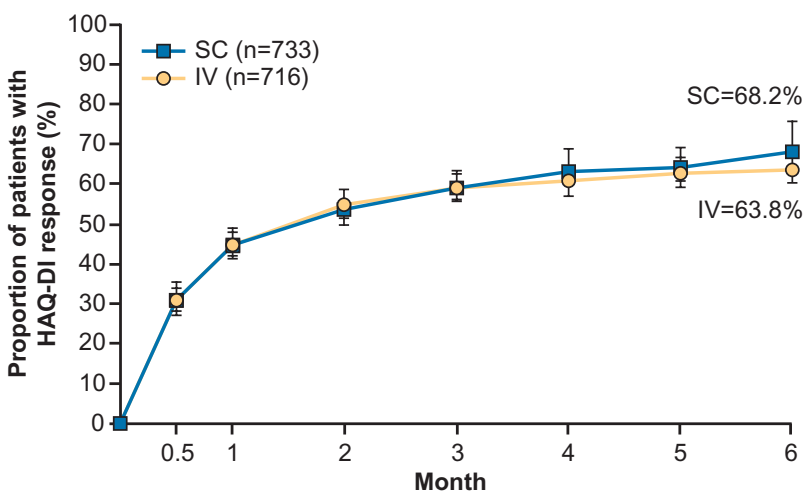

Figure 2 Proportion of patients treated with SC or IV abatacept as part of the ACQUIRE study achieving a HAQ-DI response over 6 months of treatment (ITT population).

Notes: HAQ-DI response defined as an improvement of $\geq 0.3$ units from baseline. Reproduced with permission from John Wiley and Sons. Copyright (c) 2011 by the American College of Rheumatology. Genovese MC, Covarrubias A, Leon G, et al. Subcutaneous abatacept versus intravenous abatacept: a phase Illb noninferiority study in patients with an inadequate response to methotrexate. Arthritis Rheum. 20II;63(I0):2854-2864. ${ }^{26}$

Abbreviations: ACQUIRE, Abatacept Comparison of Sub[QU]cutaneous versus Intravenous in inadequate Responders to methotrexatE; HAQ-DI, Health Assessment Questionnaire-Disability Index; ITT, intention-to-treat; IV, intravenous; SC, subcutaneous.

SC and IV groups, respectively. ${ }^{26}$ The adjusted mean (SEM) percent improvement in patient's global assessment of disease activity from baseline to month 6 was comparable between the two formulations: $48.1 \%$ (1.66) versus $47.4 \%$ (1.68) for the SC and IV abatacept groups, respectively (adjusted difference between groups: $0.7 \%$ [95\% CI: $-3.9,5.4]) .{ }^{26}$ Patient-assessed pain was comparable for SC and IV abatacept, with adjusted mean (SEM) improvements from baseline to month 6 of $49.1 \%$ (1.74) and 44.9\% (1.77), respectively (adjusted difference between groups: $4.2 \%$ [95\% CI: $-0.7,9.1]){ }^{26}$

Although the availability of PRO data for $\mathrm{SC}$ abatacept is currently limited, data from trials of IV abatacept demonstrate significantly greater improvements in a range of HRQoL measures compared with nonbiologic DMARD treatment. , $7,12,36-42^{2}$ These findings, combined with data from the ACQUIRE study, demonstrate that abatacept leads to significant improvements in PROs associated with RA, including key outcomes related to HRQoL such as pain and physical function.

\section{Can patients switch from IV to SC abatacept with maintained efficacy and without increased safety concerns?}

Clinicians may choose to switch patients from IV to SC abatacept, for example due to patient preference for self-administered therapy. The primary end point of the ATTUNE study (Table 1) was to evaluate safety during the first 3 months after switching from long-term IV to SC abatacept in patients who had previously completed $\geq 4$ years of treatment with IV abatacept 
during the AIM or ATTAIN studies. ${ }^{43-46}$ AEs were reported in $39.8 \%(n=49)$ of patients during the first 3 months; one patient discontinued due to an AE (musculoskeletal pain) and one patient experienced an SAE (worsening of RA, moderate intensity; patient continued treatment). ${ }^{47}$ No serious infections, malignancies, or autoimmune events occurred during this time. One serious infection (pneumonia), two malignancies (breast and uterine cancer), and two autoimmune events (sarcoidosis and erythema nodosum) were reported after month 3 . Two patients experienced mild injection-site reactions ([ISRs] erythema and pain), both following their first SC abatacept injection; no ISRs were reported after month 3 . No new safety events were reported and no deaths occurred. ${ }^{47}$ The presence of anti-abatacept antibodies was assessed using an enzyme-linked immunosorbent assay and an electrochemiluminescence immunoassay. Immunogenicity (positive response to anti-abatacept antibodies) was detected in eight patients, six of whom were seropositive prior to enrollment in the ATTUNE study. Immunogenicity did not appear to impact safety or efficacy in these patients. ${ }^{47}$

Throughout the ATTUNE study, patients demonstrated maintained clinical responses following the switch from long-term IV to SC abatacept, with the proportions of patients in DAS28 (CRP)-derived low disease activity state or remission at baseline being maintained through 12 months of treatment with SC abatacept. ${ }^{47}$ These findings are also supported by the PRO HAQ-DI, which showed that improvements in physical function achieved during previous treatment with IV abatacept in the AIM or ATTAIN studies were maintained through to month 12 (Figure 3).

These findings demonstrate that patients who have been receiving abatacept via IV infusion can easily switch to self-administered SC injections, if they wish, without loss of efficacy and with no increased safety concerns or risk of immunogenicity.

\section{If a patient is treated with the SC formulation of abatacept, do they first need an IV abatacept loading dose?}

In routine clinical practice in USA and the $\mathrm{EU}, \mathrm{SC}$ abatacept is initiated following a single IV infusion of $\sim 10 \mathrm{mg} / \mathrm{kg}$

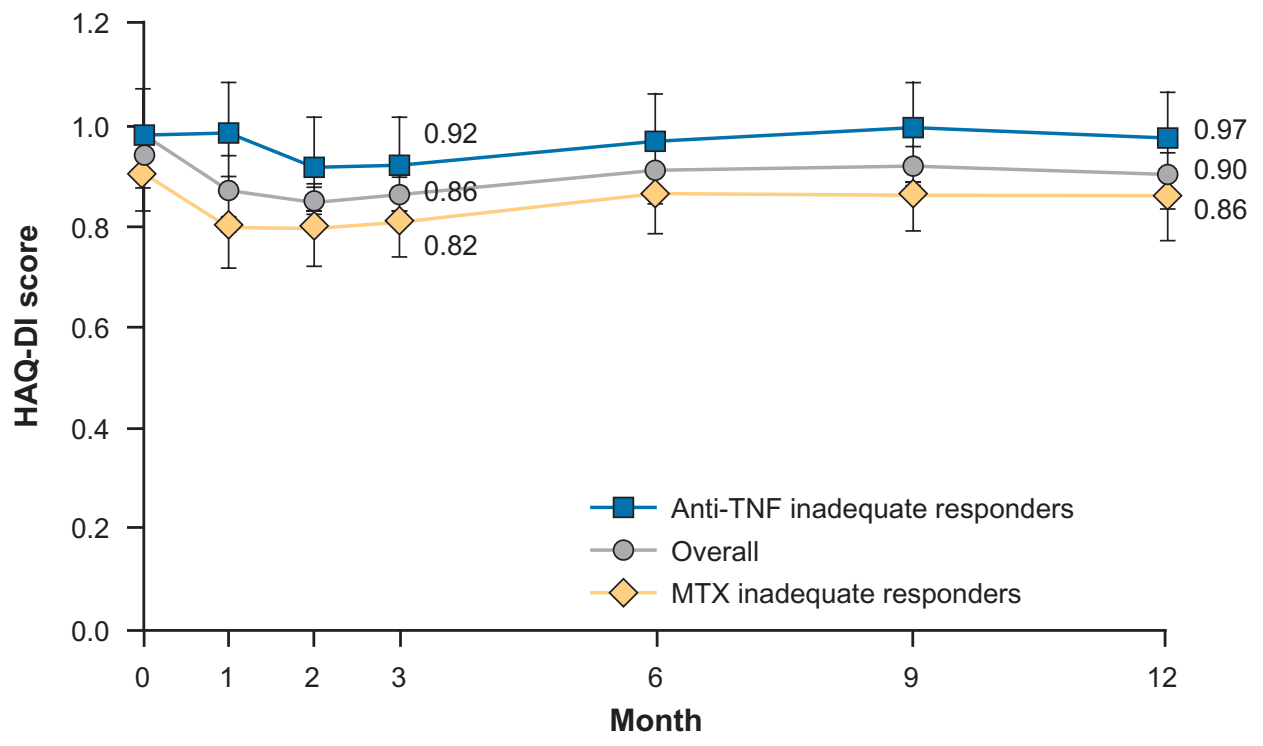

\begin{tabular}{|l|c|c|c|c|c|c|c|}
\hline Month & 0 & 1 & 2 & 3 & 6 & 9 & 12 \\
\hline MTX inadequate responders, ${ }^{*} \mathrm{n}$ & 71 & 69 & 71 & 71 & 71 & 71 & 69 \\
\hline TNF inadequate responders, ${ }^{\dagger} \mathrm{n}$ & 52 & 51 & 50 & 49 & 49 & 47 & 45 \\
\hline Overall, $\mathrm{n}$ & 123 & 120 & 121 & 120 & 120 & 118 & 114 \\
\hline
\end{tabular}

Figure 3 Physical function (mean HAQ-DI score) over I year for patients in the ATTUNE study.

Notes: Error bars represent standard error of mean HAQ-DI scores. *Participated in AIM; ${ }^{\dagger}$ participated in ATTAIN. Reproduced with permission from BMJ Publishing Group Ltd. Copyright (C) 2012. Keystone EC, Kremer JM, Russell A, et al. Abatacept in subjects who switch from intravenous to subcutaneous therapy: results from the phase IIlb ATTUNE study. Ann Rheum Dis. 20I2;7I(6):857-86I. ${ }^{47}$

Abbreviations: AIM, Abatacept in Inadequate responders to Methotrexate; ATTAIN, Abatacept Trial in Treatment of Anti-TNF INadequate responders; ATTUNE, Abatacept in subjecTs who swiTch from intravenoUs to subcutaNeous thErapy; HAQ-DI, Health Assessment Questionnaire-Disability Index; MTX, methotrexate; TNF, tumor necrosis factor. 
abatacept, given on day 1 of SC abatacept treatment as an IV "loading dose", in patients who are unable to receive an infusion, SC abatacept may be initiated without an IV loading dose. ${ }^{48,49}$ Post hoc analyses of clinical data reveal comparable efficacy and safety of SC abatacept when administered either with or without prior IV loading.

A comparison of pharmacokinetic data from the ALLOW and ACCOMPANY studies has shown comparable target therapeutic serum concentrations being achieved by day 15 of SC abatacept treatment, with and without IV loading, respectively. ${ }^{50}$ Improvements in disease activity at month 3 , measured by percent change in mean $(95 \% \mathrm{CI})$ DAS28 (CRP) scores from baseline, were comparable for patients treated with $(-31.6[-35.5,-27.7])$ or without $(-27.8[-32.8,-22.9])$ IV loading. ${ }^{51}$ The occurrence of SAEs, including infections, was also similar for patients from both studies. ${ }^{50,51}$

A similar comparison of efficacy outcomes from the ACQUIRE (with IV loading) and Abatacept versus adaliMumab comParison in bioLogic-naïve RA subjects with background mEthotrexate ([AMPLE] without IV loading) studies revealed comparable ACR20 response rates and improvements in physical function, as measured by HAQ-DI response rates, and disease activity, as measured by DAS28 (CRP), over 6 months of SC abatacept treatment. ${ }^{52}$ When analyses were restricted to patients with a baseline DAS28 (CRP) of $>5.1$, thus taking into account differences in baseline disease activity between the two study populations, mean changes in DAS28 (CRP) over time remained comparable between the two studies. ${ }^{52}$

These findings suggest that SC abatacept can be administered either with or without prior IV loading, making it a convenient treatment option in cases when IV administration is undesirable, for example in patients with poor venous access or those with a preference to receive treatment at home due to limited mobility.

\section{Can patients interrupt treatment with SC abatacept without loss of long-term efficacy and without increased safety concerns upon reinitiation?}

Some patients with RA may require temporary interruption of treatment, for example in the event of surgery or due to AEs. ${ }^{53}$ Key concerns for patients following periods of temporary treatment interruption may include loss of long-term efficacy or increased risk to safety (eg, ISRs) on reintroduction.

The coprimary end points of the ALLOW study (Table 1) were safety and immunogenicity after 3 months of withdrawal of SC abatacept. ${ }^{53}$ This study consisted of three 12-week treatment periods: during period I, patients received an IV loading dose $(\sim 10 \mathrm{mg} / \mathrm{kg})$ on day 1 , followed by weekly SC abatacept $(125 \mathrm{mg})$; during period II, patients were randomly assigned (2:1) to withdraw abatacept (SC placebo) or continue taking SC abatacept; and during period III, patients receiving $\mathrm{SC}$ abatacept continued treatment and patients on placebo were reintroduced to SC abatacept.

The proportion of patients experiencing an AE during periods II and III of the ALLOW study were comparable between the SC abatacept and placebo groups (period II: $32.5 \%$ vs $36.3 \%$; period III: $37.5 \%$ vs $41.8 \%$ ). Most AEs were of mild or moderate intensity. ${ }^{53}$ SAEs were reported in six patients: three in period I, two in period II (both SC placebo), and one in period III (SC placebo). One patient died due to a pulmonary embolism in period I; all other SAEs resolved. ${ }^{53}$ Incidence of infection was comparable between the SC abatacept and placebo groups (period II: $12.5 \%$ vs $8.8 \%$; period III: $17.5 \%$ vs $19.0 \%$ ). One serious infection was reported (cellulitis during period I, leading to discontinuation). ${ }^{53}$ No malignancies or autoimmune events were reported during the study. ${ }^{53}$ Two ISRs were reported, both in period I and both mild in intensity. No ISRs were reported on reintroduction of SC abatacept. ${ }^{53}$ A nonsignificant increase in immunogenicity was observed following the 3-month withdrawal of abatacept (period II: $9.6 \%$ SC placebo vs $0 \%$ SC abatacept; $P=0.119$ ), which was reversed on reintroduction of SC abatacept (end of period III: $2.7 \%$ vs $2.6 \%$, respectively). ${ }^{53}$

Temporary withdrawal of SC abatacept resulted in a slight worsening in efficacy, which was reversed on reintroduction of SC abatacept. ${ }^{53}$ By the end of period III, 3 months after reintroduction, improvements in disease activity were comparable between patients who had received continuous SC abatacept and those who had had SC abatacept temporarily withdrawn (mean change [95\% CI] in DAS28 [CRP] score from baseline: $-2.22[-2.50,-1.94]$ vs -2.32 $[-2.56,-2.09]) .{ }^{53}$ These findings of comparable improvements in disease activity between the two treatment groups are also reflected in patient-reported improvements in physical function. For patients who were maintained on SC abatacept throughout the ALLOW study, improvements in physical function (assessed by change in HAQ-DI score from baseline) observed during the 3-month introduction phase (period I) persisted up to period III (Figure 4). ${ }^{53}$ For patients who were withdrawn from SC abatacept during period II (SC placebo group), mean reductions in HAQ-DI deteriorated slightly following withdrawal and improved on reintroduction in period III (Figure 4). ${ }^{53}$

These findings suggest that patients receiving treatment with SC abatacept can undergo temporary treatment 


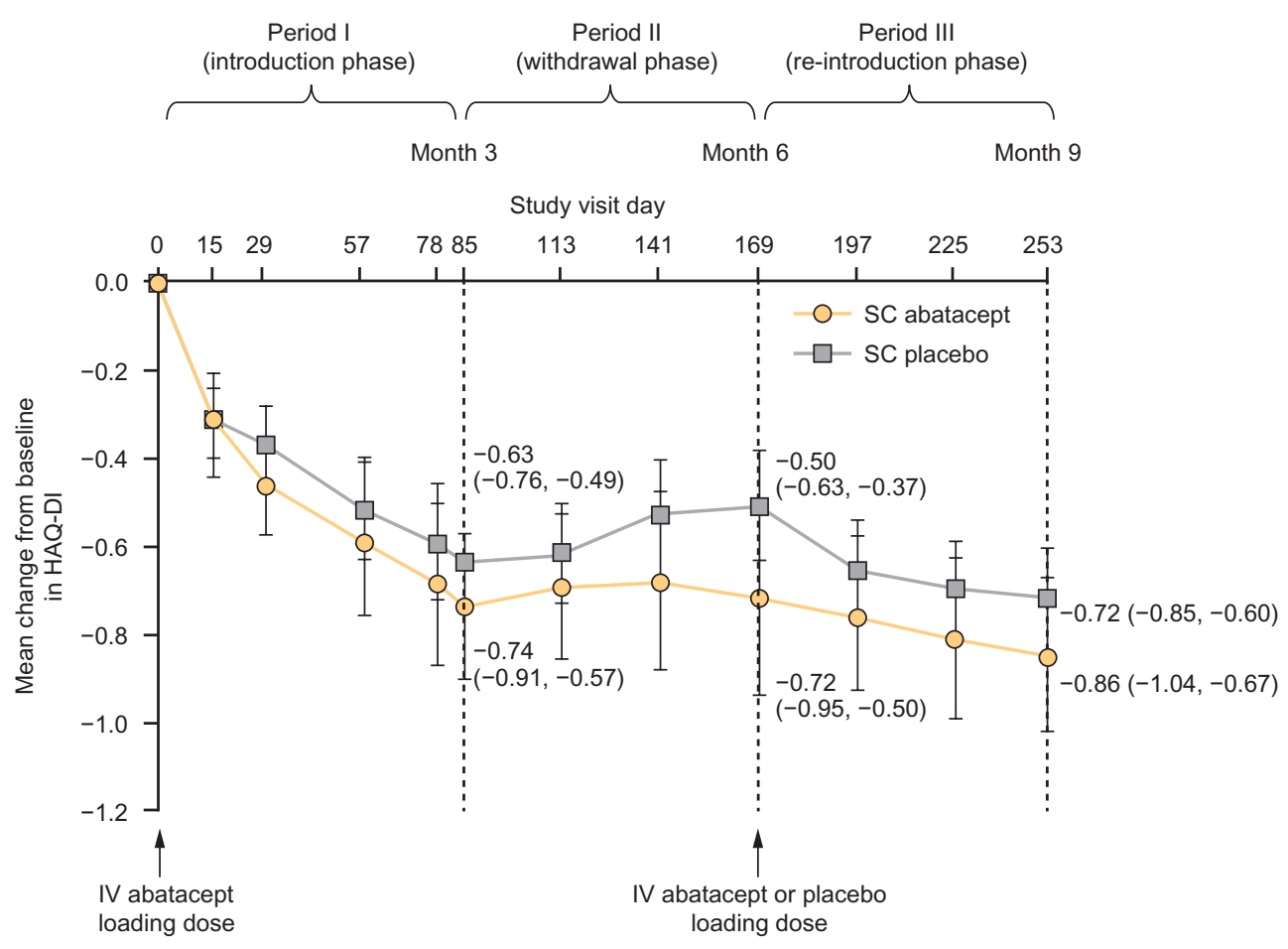

Figure 4 Change in physical function (mean change in HAQ-DI score) for patients in the ALLOW study.

Notes: Data are as observed for all patients who received $\geq$ I dose of study drug during period II. Error bars represent $95 \%$ confidence interval. Copyright $($ C Kaine J, et al. Evaluation of abatacept administered subcutaneously in adults with active rheumatoid arthritis: impact of withdrawal and reintroduction on immunogenicity, efficacy and safety (phase liib ALLOW study). Ann Rheum Dis. 2012;7I(I):38-44..$^{53}$

Abbreviations: ALLOW, Evaluation of Abatacept administered subcutaneousLy in aduLts with active rheumatOid arthritis: impact of Withdrawal and reintroduction on immunogenicity, efficacy and safety; HAQ-DI, Health Assessment Questionnaire-Disability Index; IV, intravenous; SC, subcutaneous.

interruption without an increased risk to safety or reduced tolerability. A slight worsening of disease activity and physical function may be observed during withdrawal; however, this appears to be reversed following reintroduction.

\section{Can patients receive SC abatacept as monotherapy without the loss of efficacy and without increased safety concerns?}

Many biologic DMARDs are administered in combination with MTX to improve efficacy outcomes or to reduce the risk of immunogenicity; however, some patients are intolerant to MTX. The primary end point of the ACCOMPANY study (Table 1) was to assess the rate of immunogenicity over 4 months of treatment with SC abatacept, with or without concomitant MTX. ${ }^{54}$

During the 4-month treatment period, immunogenicity rates were low in both the SC abatacept monotherapy and combination arms $(2.0 \%$ vs $3.9 \%) .{ }^{54}$ All events were transient and associated with low titers, and no positive antibody responses were observed at the end of month $4 .{ }^{54}$ Immunogenicity did not appear to impact safety or efficacy, other than one patient experiencing mild/moderate paresthesia, mild rash, and moderate worsening of constipation at the same time as demonstrating seropositivity. ${ }^{54}$

Similar safety profiles were also observed in the monotherapy and combination arms of the ACCOMPANY study, with a comparable proportion of patients in each arm experiencing AEs (65.3\% vs $72.5 \%$, respectively).$^{54}$ Infections were reported in $28.6 \%$ of patients in the monotherapy arm and $35.3 \%$ in the combination arm; serious infections were reported in two patients in the monotherapy arm and one in the combination arm. ${ }^{54}$ No malignancies, autoimmune events, or deaths were reported during the 4-month ACCOMPANY study. ${ }^{54}$ Five patients experienced SAEs: three in the monotherapy arm (moderate cartilage injury, moderate lower respiratory infection, and severe pneumonia) and two in the combination arm (severe pneumonia and severe syncope).$^{54}$ ISRs were reported in four $(8.2 \%)$ patients in the monotherapy group and in three $(5.9 \%)$ patients in the combination group; all events were mild and none led to discontinuation. ${ }^{54}$

Comparable improvements in disease activity were observed in both the monotherapy and combination arms (mean $[95 \% \mathrm{CI}$ ] change in DAS28 [CRP] from baseline to month $4:-1.94[-2.46,-1.42]$ vs -1.67 [-2.06, -1.28$]$, respectively). ${ }^{54}$ Improvements in physical function were 
also reported by patients in both groups (mean change [95\% CI] in HAQ-DI score from baseline to month 4: -0.31 $[-0.43,-0.19]$ vs $-0.58[-0.74,-0.42]$ for the combination and monotherapy groups, respectively). ${ }^{54}$

In some patients, MTX is associated with side effects such as abnormal liver function tests and cytopenias. ${ }^{55}$ Data from the ACCOMPANY study demonstrate comparable clinical efficacy, safety, and tolerability in patients treated with SC abatacept monotherapy compared with those receiving concomitant MTX, suggesting that SC abatacept monotherapy may be a practical treatment option in this patient group.

\section{Does SC abatacept have comparable efficacy, safety, and tolerability to other biologic DMARDs? Head-to-head data}

Until recently, decisions regarding choice of treatment for RA have been restricted by a lack of head-to-head studies. However, head-to-head data are now available for a small number of biologic DMARDS, including SC abatacept (AMPLE study), and can provide an invaluable source of evidence for physicians and patients alike.

\section{Clinical efficacy}

AMPLE met its primary end point by demonstrating that SC abatacept plus MTX was noninferior to SC adalimumab plus MTX, as assessed by ACR20 response at month 12 (64.8\% SC abatacept vs $63.4 \%$ adalimumab; estimated difference between treatments: $1.8 \%$ [95\% CI: -5.6, 9.2]; intention-totreat analysis). ${ }^{56}$ Similar kinetics of ACR20/50/70 response were also observed for the two treatments, with similar times to onset and duration of response. ${ }^{56}$ Inhibition of radiographic damage was also assessed, with $84.8 \%$ of patients in the SC abatacept and $88.6 \%$ in the adalimumab arm experiencing no radiographic progression at 1 year (defined as a total modified Sharp-van der Heijde score less than or equal to the smallest detectable change; estimated difference between treatments: $4.1 \%[95 \%$ CI: $-1.5,9.6]) .{ }^{56}$

\section{PROs}

As well as presenting measures of clinical efficacy, a range of PROs have also been published from year 1 of the ongoing AMPLE study, including HAQ-DI, patient assessment of disease activity, patient-assessed pain, and fatigue, as well as the composite measures SF-36 and Routine Assessment of Patient Index Data 3 ([RAPID3] which comprises three patient-reported measures: physical function, pain, and patient's global assessment of disease activity).
Assessing patient-reported improvements in physical function over time reveals comparable kinetics of response for the SC abatacept and adalimumab treatment groups (Figure 5), with adjusted mean (SEM) changes in HAQ-DI
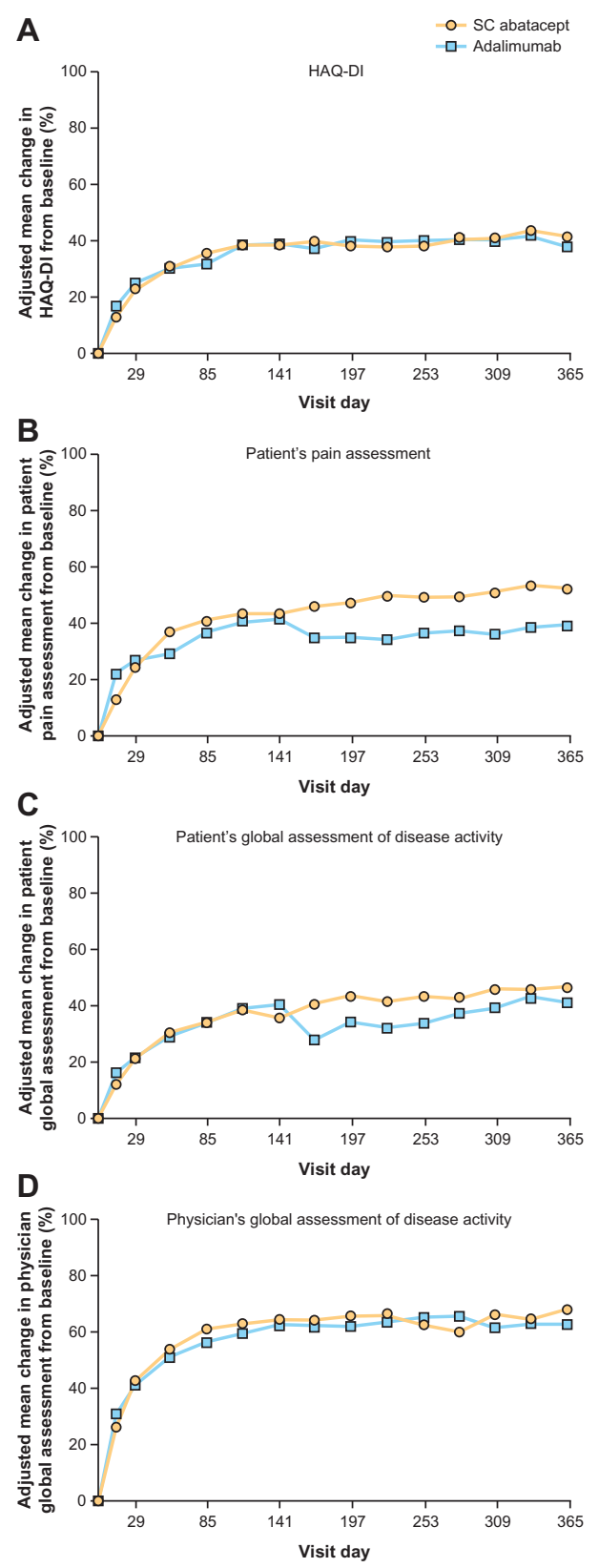

Figure 5 Mean change from baseline to year I of four components of the American College of Rheumatology core set of outcomes measures, assessed in patients treated with SC abatacept or adalimumab in the AMPLE study.

Notes: (A) HAQ-DI; (B) patient's pain assessment; (C) patient's global assessment of disease activity; (D) physician's global assessment of disease activity. Data are adjusted mean change at I year from baseline. Reproduced with permission from John Wiley and Sons. Copyright (c) 2013 by the American College of Rheumatology. Weinblatt ME, Schiff M, Valente R, et al. Head-to-head comparison of subcutaneous abatacept versus adalimumab for rheumatoid arthritis: findings of a phase Illb, multinational, prospective, randomized study. Arthritis Rheum. 2013;65(1):28-38. ${ }^{56}$

Abbreviations: AMPLE, Abatacept versus adaliMumab comParison in bioLogicnaïve RA subjects with background mEthotrexate; HAQ-DI, Health Assessment Questionnaire-Disability Index; SC, subcutaneous. 
score from baseline to year 1 of $-0.60(0.04)$ and $-0.59(0.03)$, respectively. ${ }^{56}$ At day 29 of the AMPLE study, similar proportions of patients in the SC abatacept and adalimumab groups had achieved a HAQ-DI response (42.8\% [95\% CI: 37.3, 48.2] vs $44.8 \%$ [95\% CI: 39.4, 50.2]); ${ }^{.57}$ by the end of year 1, 60.4\% (95\% CI: $55.0,65.8)$ and $57.0 \%$ (95\% CI: 51.7 , 62.4), respectively, were HAQ-DI responders (estimate of difference: $3.4 \%$ [95\% CI: $-4.5,11.3]) .{ }^{56}$

While similar trends were observed between SC abatacept and adalimumab for physician's global assessment of disease activity over year 1 , differences were found between the two treatments with regard to patient's global assessment of disease activity (Figure 5). ${ }^{56,57}$ Mean (SEM) percent improvements in patient's global assessment of disease activity for the SC abatacept and adalimumab groups were $40.2 \%$ (7.3) and $27.6 \%$ (7.2) at month 6, and 46.1\% (3.5) and $41.2 \%$ (3.4) at year 1 (adjusted mean difference between treatment groups at year 1: $4.9 \%$ [95\% CI: $-4.4,14.1]) .56,57$ In comparison, percent improvements in physician's global assessment of disease activity at year 1 were $68.5 \%$ (4.3) and $63.0 \%$ (4.3) in the SC abatacept and adalimumab groups, respectively (adjusted mean difference $-5.5 \%$ [95\% CI $-6.0,17.0]) .56$

Differences in mean (SEM) percent improvements in pain were observed for patients in the SC abatacept versus adalimumab groups at both 6 months (46.5\% [4.2] vs 35.6\% [4.1]) and at 1 year $(53.0 \%$ [6.1] vs 39.2\% [6.0]; adjusted difference between groups at year 1: 13.8\% [95\% CI: -2.5 , 30.1])..$^{56,57}$

During year 1 of the AMPLE study, patient fatigue improved in both the SC abatacept and adalimumab groups (mean $[\mathrm{SEM}]$ percent change in fatigue score from baseline to month $6:-22.4 \%$ [1.5] vs $-19.9 \%$ [1.5]; from baseline to year 1: $-23.2 \%$ [1.5] vs $-21.4 \%$ [1.5]; adjusted mean difference between treatment groups at year 1: $-1.8 \%[95 \%$ CI: $-5.8,2.2]) .^{56,57}$

Improvements in all domains of the SF-36 Health Survey, including both physical and mental component summary scores, were observed at 6 months in the AMPLE study and were maintained up to 1 year in both the SC abatacept and adalimumab groups (Figure 6). ${ }^{56,57}$

Improvements in RAPID3 scores for disease activity were similar for both SC abatacept and adalimumab during year 1 of the AMPLE study (mean change [standard error (SE)] from baseline to month $6:-2.7(0.1)$ vs $-2.5(0.1)$; mean [SE] change from baseline to year 1 : $-2.9(0.1)$ vs $-2.7(0.1)) .{ }^{57}$

These findings generally demonstrate comparable improvements and kinetics of response for a range of HRQoL outcomes for SC abatacept and adalimumab plus MTX.

\section{Safety}

The safety profiles of SC abatacept and adalimumab were generally similar, with comparable rates of AEs, SAEs,

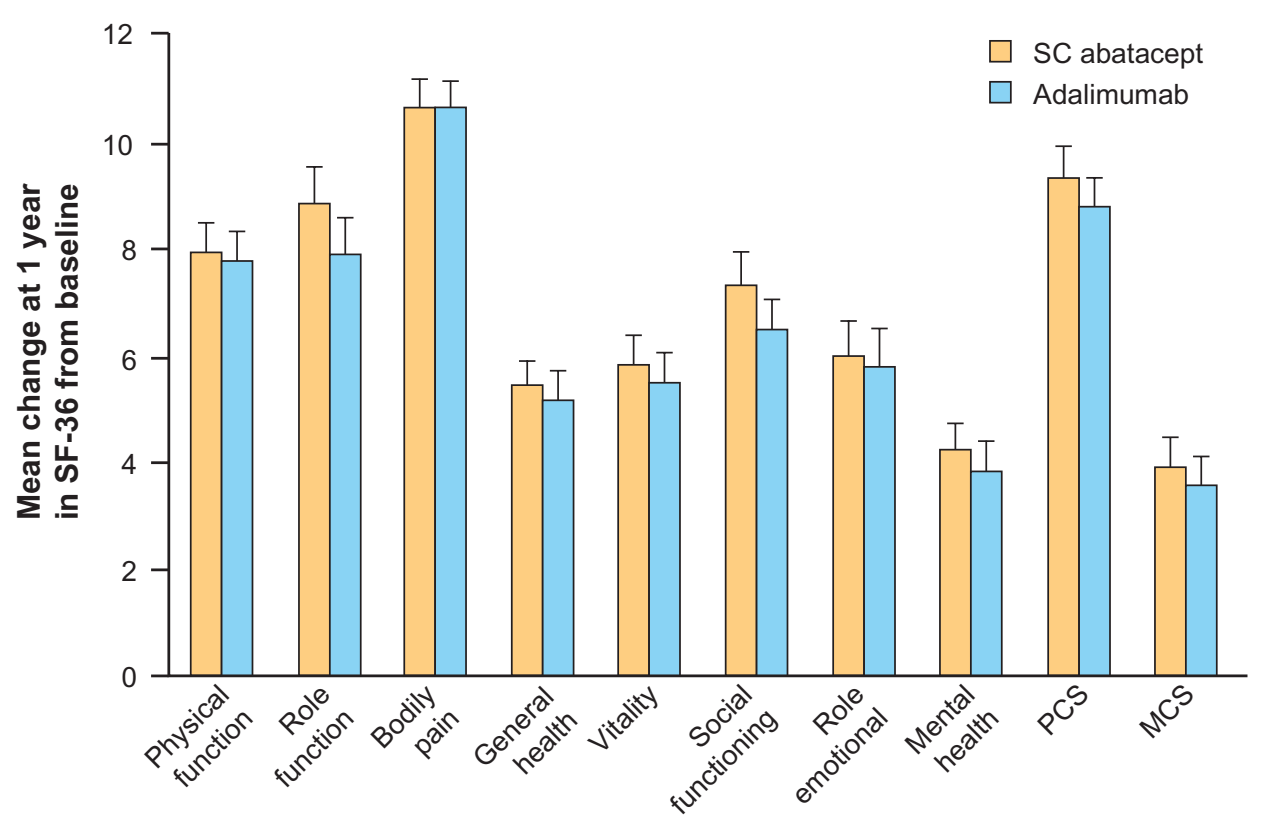

Figure 6 Mean change from baseline to year I in SF-36 Health Survey scores in patients treated with SC abatacept or adalimumab in the AMPLE study. Notes: Reproduced with permission from John Wiley and Sons. Copyright @ 2012 by the American College of Rheumatology. Fleischmann R, Weinblatt ME, Schiff MH, Khanna D, Furst D, Maldonado MA. Changes in patient reported outcomes in response to subcutaneous abatacept or adalimumab in rheumatoid arthritis:results from the AMPLE (abatacept versus adalimumab comparison in biologic naive RA subjects with background methotrexate) trial. Arthritis Rheum. 20I2;64(Suppl I0):S578. ${ }^{57}$

Abbreviations: AMPLE, Abatacept versus adaliMumab comParison in bioLogic-naïve RA subjects with background mEthotrexate; MCS, mental component summary; PCS, physical component summary; SC subcutaneous; SF-36, Short Form-36 Health Survey. 
infections, and malignancies; however, some important differences were also observed. ${ }^{56}$ Although autoimmune events were reported in more patients in the SC abatacept arm than in the adalimumab arm $(\mathrm{n}=10[3.1 \%]$ vs $\mathrm{n}=4$ [1.2\%]), rates of discontinuation due to autoimmune events were the same (one patient in each arm). ${ }^{56}$ Similar rates of serious infections were reported in the SC abatacept and adalimumab arms $(2.2 \%[n=7]$ vs $2.7 \%[n=9])$; however, five of these patients in the adalimumab arm discontinued, compared with none in the SC abatacept arm. ${ }^{56}$ Overall, fewer patients treated with SC abatacept discontinued due to AEs or SAEs compared with adalimumab (3.5\% and $1.3 \%$ vs $6.1 \%$ and 3.0\%, respectively). ${ }^{56}$ Frequency of ISRs, a predefined safety outcome, was significantly lower in the SC abatacept arm than in the adalimumab arm $(3.8 \%$ vs $9.1 \%$ [95\%
CI: $-9.13,-1.62] ; P=0.006)$; three patients in the adalimumab arm discontinued due to ISRs, compared with none in the SC abatacept arm. ${ }^{56}$

\section{Meta-analyses}

To our knowledge, data from the clinical trial program for $\mathrm{SC}$ abatacept have yet to be included in any meta-analyses comparing biologic DMARDs. However, several indirect treatment comparisons have included clinical data for IV abatacept.

Indirect comparison estimates from a Cochrane Review meta-analysis found no significant difference in efficacy between IV abatacept and five other biologics, as determined by ACR50 response rates (Figure 7). ${ }^{58} \mathrm{~A}$ second Cochrane Review meta-analysis investigating the safety of

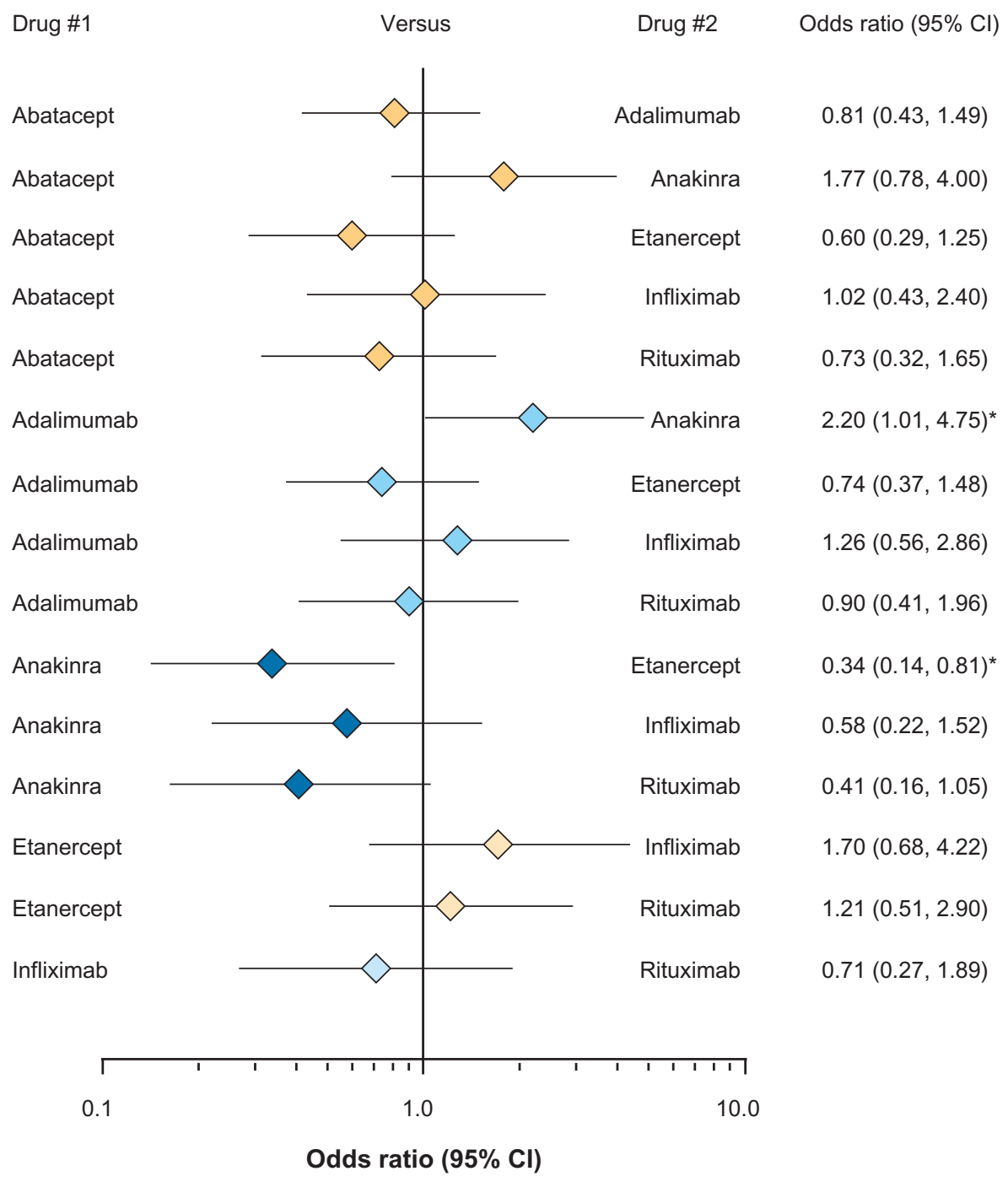

Figure 7 Forest plot comparing the probability of patients achieving an ACR50 response when treated with different biologic DMARDs (indirect treatment comparison estimates). Notes: *Significant difference between comparison drugs. Reproduced with permission from John Wiley and Sons. Copyright (C) 2013 The Cochrane Collaboration. Published by John Wiley \& Sons, Ltd. Singh JA, Christensen R, Wells GA, et al. Biologics for rheumatoid arthritis: an overview of Cochrane reviews. Cochrane Database Syst Rev. 2009;(4):CD007848. ${ }^{58}$

Abbreviations: ACR50, American College of Rheumatology 50\% improvement criteria; Cl, confidence interval; DMARD, disease-modifying antirheumatic drug. 
biologics in patients treated for any indication (except human immunodeficiency disease) found that, compared with other biologics, IV abatacept was associated with a similar risk of AEs, SAEs, and serious infections. ${ }^{59}$

Meta-analyses such as those described here can provide helpful information for physicians and patients regarding their choice of biologic for treatment of RA; however, significant heterogeneity between study populations is often detected, meaning that the findings of such analyses should be interpreted with caution.

\section{Real-world data}

There is currently a lack of real-world data for SC abatacept to help guide the selection of the most appropriate biologic for the treatment of patients with RA. Registry data for IV abatacept, however, demonstrate similar clinical efficacy between abatacept and other biologic DMARDs, including anti-TNF agents.

An analysis of data from the Consortium of Rheumatology Researchers of North America (CORRONA) registry found no significant difference in rates of modified ACR20 response or Clinical Disease Activity Index-defined remission between IV abatacept and anti-TNF agents in biologic-naïve patients with RA (odds ratio [95\% CI]: 1.04 [0.37, 2.95] and 1.62 [0.63-4.17], respectively). ${ }^{60}$ Similarly, data from the French Society of Rheumatology registries AutoImmunity and Rituximab (AIR) and Orencia and Rheumatoid Arthritis (ORA) found no significant difference between rituximab and IV abatacept for The European League Against Rheumatism (EULAR) response (odds ratio [95\% CI]: 1.00, [0.84, 1.20]), DAS28-derived low disease activity $(0.86[0.70,1.05])$, or DAS28-derived remission $\left(0.79\right.$ [0.61, 1.02]). ${ }^{61}$

Ongoing patient registries will help provide further information regarding the use of specific treatments in routine clinical practice.

\section{How important is a biologic's route of administration to patients with RA?}

Route of administration can be an important factor when choosing the most appropriate treatment option for patients. In a single-center study of 90 patients with RA, $41 \%$ of patients receiving anti-TNF therapy and $52.5 \%$ receiving nonbiologic DMARDs stated that they preferred SC administration of treatment, compared with IV or intramuscular administration. ${ }^{62}$ In addition, $62.5 \%$ of patients in the antiTNF group and $52 \%$ of patients in the nonbiologic DMARD group preferred to receive treatment at home, rather than on a day ward or as an inpatient. ${ }^{62}$ In another single-center study of 109 patients with RA, younger patients (aged $<61$ years) were found to prefer SC over IV medication, whereas older patients (aged $>61$ years) preferred treatment that was administered by health care staff, with factors such as "contact with other patients/meeting others" and "staff availability if problems arise" influencing this choice. ${ }^{63}$

Although individual patients may have a preference for a particular route of administration, the clinical trial data discussed here demonstrate that both the IV and SC formulations of abatacept are associated with high rates of patient retention. For example, in the first Phase III, randomized controlled trial of IV abatacept (AIM study), 89\% of patients who were MTX inadequate responders completed 12 months of therapy, ${ }^{7}$ with $72 \%$ and $61 \%$ of these patients being retained at years 3 and 5, respectively. ${ }^{8,45}$ Similar high retention rates $(>90 \%)$ have been observed in the short-term periods of the SC abatacept studies, ${ }^{26,47,53,54,56}$ with consistent findings in the LTE periods of these studies. During the 6-month ACQUIRE study, comparable rates of retention were seen for SC and IV abatacept, with $82.7 \%$ of patients remaining on SC abatacept treatment in the LTE at the time of last reporting (mean exposure to abatacept: 33 months [range: 8-44 months]). ${ }^{26,27}$ High retention rates were also observed during the AMPLE study, with $86.2 \%$ of patients receiving SC abatacept and $82.0 \%$ of patients receiving SC adalimumab remaining on treatment at the end of year $1,{ }^{56}$ and with $79.2 \%$ and $74.7 \%$ of patients, respectively, completing the 2 -year study. ${ }^{64}$

\section{Discussion}

There are now more therapeutic options available for the treatment of RA than ever before, increasing a clinician's ability to individualize therapy. Here, we have provided an overview of the current clinical data for the SC formulation of abatacept and have addressed several key concerns that patients and clinicians may have regarding its clinical utility.

Abatacept is the first biologic for which IV and SC formulations are available for the treatment of RA. Although many patients may prefer the convenience of SC administration of treatment in their own home, others may be uncomfortable with self-injecting and may prefer treatment administered by health care providers in an IV infusion suite. ${ }^{63}$

Although clinical data are currently limited by a smaller number of patient-years of exposure to SC abatacept compared with IV abatacept, data from the ACQUIRE study and from integrated safety analyses demonstrate comparable clinical efficacy, safety, and tolerability for IV and SC abatacept. ${ }^{26,30-32,65}$ Several studies have also shown 
IV abatacept to be associated with significant improvements in HRQoL outcomes such as pain, sleep quality, fatigue, activity, physical function, and mental health, compared with placebo. ${ }^{5,36,38-42}$ Although the availability of HRQoL data for $\mathrm{SC}$ abatacept remains limited, the data presented here show that patients receiving SC abatacept plus MTX demonstrate improvements in PROs that are comparable with those of patients receiving IV abatacept plus MTX. ${ }^{26}$

The data overviewed here also demonstrate the clinical utility of SC abatacept in different patients. Data from the ATTUNE study show that patients currently receiving IV abatacept may switch to SC administration without loss of efficacy and with no increased risk to safety. ${ }^{47}$ For patients who are not currently receiving abatacept, post hoc analyses show that SC abatacept can be initiated either with or without a prior IV abatacept loading dose, ${ }^{50-52}$ making it a practical option for patients who are unable to receive treatment via infusion. Furthermore, data from the ACCOMPANY study suggest that SC abatacept is also suitable for patients who are intolerant of or unable to receive MTX, demonstrating comparable efficacy, safety, and tolerability, regardless of whether patients received background MTX or not. ${ }^{54}$ Temporary interruption of SC abatacept may also be necessary, for example, in the event of surgery or due to AEs. Data from the ALLOW study show that temporary withdrawal of SC abatacept does not affect long-term safety or efficacy. ${ }^{53}$

With agents with different mechanisms of action and routes of administration available for the treatment of RA, choosing the best treatment option can be challenging, with many patients having to switch between therapies multiple times. Choice of treatment is often guided by indirect treatment comparisons using meta-analyses of clinical data or observational data from registries. Although there are currently no real-world data or meta-analyses comparing SC abatacept with other biologic DMARDs, treatment comparisons including IV abatacept suggest comparable efficacy between biologics for RA..$^{58,60,61}$

The first head-to-head data for SC abatacept, from the AMPLE study, support these findings by demonstrating comparable clinical efficacy, kinetics of response, and radiographic inhibition between SC abatacept and SC adalimumab over 12 months of treatment in biologic-naïve patients with RA. ${ }^{56}$ Although safety profiles were generally similar for these two biologics, some important differences were noted, including fewer discontinuations and significantly fewer ISRs with SC abatacept than with adalimumab. Data from the AMPLE study also demonstrate comparable improvements in several key PROs related to HRQoL, including physical function, disease activity, pain, and fatigue, as well as composite measures of HRQoL (SF-36) and disease activity (RAPID3).

\section{Conclusion}

The data reviewed here show that abatacept has comparable efficacy and safety in patients with RA when administered either by IV infusion or SC injection. Importantly, both formulations of abatacept are associated with significant improvements in outcomes directly related to patients' quality of life, such as loss of physical function and pain. The use of SC abatacept in different clinical situations has also been demonstrated, highlighting the clinical utility of the formulation for different patients. In summary, SC abatacept provides an important addition to the range of available therapy options for patients with RA.

\section{Acknowledgments}

Professional medical writing and editorial assistance were provided by Laura McDonagh, $\mathrm{PhD}$, at Caudex Medical and were funded by Bristol-Myers Squibb.

\section{Disclosure}

AFW has received consulting fees from Bristol-Myers Squibb. MS has received speaking fees and consulting fees from Bristol-Myers Squibb and AbbVie. The authors report no other conflicts of interest in this work.

\section{References}

1. World Health Organization. Global Burden and Incidence of Rheumatoid Arthritis. Geneva: World Health Organization; 2000.

2. Bay-Jensen AC, Wichuk S, Byrjalsen I, et al. Circulating protein fragments of cartilage and connective tissue degradation are diagnostic and prognostic markers of rheumatoid arthritis and ankylosing spondylitis. PLoS One. 2013;8(1):e54504.

3. Whalley D, McKenna SP, de Jong Z, van der Heijde D. Quality of life in rheumatoid arthritis. Br J Rheumatol. 1997;36(8):884-888.

4. Michaud K, Bombardier C, Emery P. Quality of life in patients with rheumatoid arthritis: does abatacept make a difference? Clin Exp Rheumatol. 2007;25(5 Suppl 46):S35-S45.

5. Wells G, Li T, Maxwell L, Maclean R, Tugwell P. Responsiveness of patient reported outcomes including fatigue, sleep quality, activity limitation, and quality of life following treatment with abatacept for rheumatoid arthritis. Ann Rheum Dis. 2008;67(2):260-265.

6. Westhovens R, Robles M, Ximenes AC, et al. Clinical efficacy and safety of abatacept in methotrexate-naive patients with early rheumatoid arthritis and poor prognostic factors. Ann Rheum Dis. 2009;68(12):1870-1877.

7. Kremer JM, Genant HK, Moreland LW, et al. Effects of abatacept in patients with methotrexate-resistant active rheumatoid arthritis: a randomized trial. Ann Intern Med. 2006;144(12):865-876.

8. Kremer JM, Russell AS, Emery P, et al. Long-term safety, efficacy and inhibition of radiographic progression with abatacept treatment in patients with rheumatoid arthritis and an inadequate response to methotrexate: 3-year results from the AIM trial. Ann Rheum Dis. 2011;70(10):1826-1830. 
9. Smolen J, Dougados M, Gaillez C, et al. Remission according to different composite disease activity indices in biologic-naïve patients with rheumatoid arthritis treated with abatacept or infliximab plus methotrexate. Arthritis Rheum. 2011;63(Suppl 10):1124.

10. Westhovens R, Kremer JM, Emery P, et al. Consistent safety and sustained improvement in disease activity and treatment response over 7 years of abatacept treatment in biologic-naïve patients with RA [Abstract SAT0108]. Ann Rheum Dis. 2009;68(Suppl 3):577.

11. Weinblatt M, Combe B, Covucci A, Aranda R, Becker JC, Keystone E. Safety of the selective costimulation modulator abatacept in rheumatoid arthritis patients receiving background biologic and nonbiologic disease-modifying antirheumatic drugs: a one-year randomized, placebo-controlled study. Arthritis Rheum. 2006;54(9):2807-2816.

12. Genovese MC, Becker JC, Schiff M, et al. Abatacept for rheumatoid arthritis refractory to tumor necrosis factor alpha inhibition. $N$ Engl $J$ Med. 2005;353(11):1114-1123.

13. Schiff M, Pritchard C, Huffstutter JE, et al. The 6-month safety and efficacy of abatacept in patients with rheumatoid arthritis who underwent a washout after anti-tumour necrosis factor therapy or were directly switched to abatacept: the ARRIVE trial. Ann Rheum Dis. 2009;68(11): 1708-1714.

14. Cutolo M, Nadler S. Advances in CTLA-4-Ig-mediated modulation of inflammatory cell and immune response activation in rheumatoid arthritis. Autoimmun Rev. 2013;12(7):758-767.

15. Yamada A, Salama A, Sayegh M. The role of novel T cell costimulatory pathways in autoimmunity and transplantation. J Am Soc Nephrol. 2002;13(2):559-575.

16. Monaco C, Andreakos E, Kiriakidis S, Feldmann M, Paleolog E. T-cell-mediated signalling in immune, inflammatory and angiogenic processes: the cascade of events leading to inflammatory diseases. Curr Drug Targets Inflamm Allergy. 2004;3(1):35-42.

17. Linsley PS, Nadler SG. The clinical utility of inhibiting CD28-mediated costimulation. Immunol Rev. 2009;229(1):307-321.

18. Koenders MI, Marijnissen RJ, Joosten LA, et al. T cell lessons from the rheumatoid arthritis synovium SCID mouse model: CD3-rich synovium lacks response to CTLA-4ig but is successfully treated by interleukin-17 neutralization. Arthritis Rheum. 2012;64(6):1762-1770.

19. Scarsi M, Ziglioli T, Airò P. Decreased circulating CD28-negative $\mathrm{T}$ cells in patients with rheumatoid arthritis treated with abatacept are correlated with clinical response. J Rheumatol. 2010;37(5): 911-916.

20. Scarsi M, Ziglioli T, Airo' P. Baseline numbers of circulating CD28negative $\mathrm{T}$ cells may predict clinical response to abatacept in patients with rheumatoid arthritis. J Rheumatol. 2011;38(10):2105-2111.

21. Platt AM, Gibson VB, Patakas A, et al. Abatacept limits breach of selftolerance in a murine model of arthritis via effects on the generation of T follicular helper cells. J Immunol. 2010;185(3):1558-1567.

22. Ndejembi MP, Teijaro JR, Patke DS, et al. Control of memory CD4 $\mathrm{T}$ cell recall by the CD28/B7 costimulatory pathway. J Immunol. 2006;177(11):7698-7706.

23. Teijaro JR, Njau MN, Verhoeven D, et al. Costimulation modulation uncouples protection from immunopathology in memory $\mathrm{T}$ cell responses to influenza virus. J Immunol. 2009;182(11):6834-6843.

24. Ko HJ, Cho ML, Lee SY, et al. CTLA4-Ig modifies dendritic cells from mice with collagen-induced arthritis to increase the CD4+CD25+Foxp3+ regulatory T cell population. J Autoimmun. 2010;34(2):111-120.

25. Álvarez-Quiroga C, Abud-Mendoza C, Doníz-Padilla L, et al. CTLA-4-Ig therapy diminishes the frequency but enhances the function of Treg cells in patients with rheumatoid arthritis. J Clin Immunol. 2011;31(4):588-595.

26. Genovese MC, Covarrubias A, Leon G, et al. Subcutaneous abatacept versus intravenous abatacept: a phase IIIb noninferiority study in patients with an inadequate response to methotrexate. Arthritis Rheum. 2011;63(10):2854-2864.

27. Genovese M, Pacheco-Tena C, Covarrubias A, et al. Subcutaneous abatacept: long-term data from the ACQUIRE Trial. Arthritis Rheum. 2012;64(Supp1 10):S201.
28. Genant H, Peterfy C, Westhovens R, et al. Abatacept increases the proportion of patients who remain free from structural damage progression through 5 years in methotrexate inadequate responders with RA. Ann Rheum Dis. 2009;68(Suppl 3):440.

29. Genovese MC, Schiff M, Luggen M, et al. Longterm safety and efficacy of abatacept through 5 years of treatment in patients with rheumatoid arthritis and an inadequate response to tumor necrosis factor inhibitor therapy. J Rheumatol. 2012;39(8):1546-1554.

30. Alten R, Kaine J, Keystone EC, et al. Safety of subcutaneous abatacept in patients with rheumatoid arthritis (RA): Integrated analysis of five clinical trials up to 4.5 years. Ann Rheum Dis. 2011;70(Suppl 3):617.

31. Hochberg MC, Westhovens R, Aranda R, Kelly SM, Khan N, Qi K. Longterm safety of abatacept: Integrated analysis of clinical program data of up to 7 years of treatment. Arthritis Rheum. 2010;62(Suppl 10):S164.

32. Alten R, Kaine J, Keystone EC, et al. Safety profile of subcutaneous abatacept focusing on clinically relevant events in patients with rheumatoid arthritis (RA) and up to 4.5 years of exposure. Arthritis Rheum. 2011;63(Suppl 10):S150.

33. Pollard L, Choy EH, Scott DL. The consequences of rheumatoid arthritis: quality of life measures in the individual patient. Clin Exp Rheumatol. 2005;23(5 Suppl 39):S43-S52.

34. Kirwan JR, Hewlett SE, Heiberg T, et al. Incorporating the patient perspective into outcome assessment in rheumatoid arthritis - progress at OMERACT 7. J Rheumatol. 2005;32(11):2250-2256.

35. Rupp I, Boshuizen HC, Jacobi CE, Dinant HJ, van den Bos GA. Impact of fatigue on health-related quality of life in rheumatoid arthritis. Arthritis Rheum. 2004;51(4):578-585.

36. Li T, Wells G, Westhovens R, Emery P, Becker JC, Tugwell P. Improvements in participation in usual daily activities in patients with rheumatoid arthritis treated with abatacept. Value Health. 2011;14(2):361-370.

37. Wells G, Li T, Maxwell L, Maclean R, Tugwell P. Determining the minimal clinically important differences in activity, fatigue, and sleep quality in patients with rheumatoid arthritis. J Rheumatol. 2007;34(2):280-289.

38. Westhovens R, Cole JC, Li T, et al. Improved health-related quality of life for rheumatoid arthritis patients treated with abatacept who have inadequate response to anti-TNF therapy in a double-blind, placebo-controlled, multicentre randomized clinical trial. Rheumatology (Oxford). 2006;45(10):1238-1246.

39. Schiff M, Keiserman M, Codding C, et al. Efficacy and safety of abatacept or infliximab vs placebo in ATTEST: a phase III, multi-centre, randomised, double-blind, placebo-controlled study in patients with rheumatoid arthritis and an inadequate response to methotrexate. Ann Rheum Dis. 2008;67(8):1096-1103.

40. Wells G, Li T, Tugwell P. Investigation into the impact of abatacept on sleep quality in patients with rheumatoid arthritis, and the validity of the MOS-Sleep questionnaire Sleep Disturbance Scale. Ann Rheum Dis. 2010;69(10):1768-1773.

41. Russell AS, Wallenstein GV, Li T, et al. Abatacept improves both the physical and mental health of patients with rheumatoid arthritis who have inadequate response to methotrexate treatment. Ann Rheum Dis. 2007;66(2):189-194.

42. Emery P, Kosinski M, Li T, et al. Treatment of rheumatoid arthritis patients with abatacept and methotrexate significantly improved healthrelated quality of life. J Rheumatol. 2006;33(4):681-689.

43. Genovese MC, Schiff M, Luggen M, et al. Efficacy and safety of the selective co-stimulation modulator abatacept following 2 years of treatment in patients with rheumatoid arthritis and an inadequate response to anti-tumour necrosis factor therapy. Ann Rheum Dis. 2008;67(4): $547-554$.

44. Kremer JM, Genant HK, Moreland LW, et al. Results of a two-year followup study of patients with rheumatoid arthritis who received a combination of abatacept and methotrexate. Arthritis Rheum. 2008;58(4): 953-963.

45. Kremer J, Russell A, Emery P, et al. Abatacept demonstrates consistent safety and sustained improvements in efficacy through 5 years of treatment in biologic-naïve patients with RA. Ann Rheum Dis. 2009;68 (Suppl 3):444. 
46. Genovese M, Schiff M, Luggen M, et al. Abatacept demonstrates consistent safety and sustained improvements in efficacy through 4 years of open-label treatment in patients with an inadequate response to anti-TNF therapy. Arthritis Rheum. 2009;60(Suppl 10):1689.

47. Keystone EC, Kremer JM, Russell A, et al. Abatacept in subjects who switch from intravenous to subcutaneous therapy: results from the phase IIIb ATTUNE study. Ann Rheum Dis. 2012;71(6):857-861.

48. Orencia $125 \mathrm{mg}$ solution for injection (pre-filled syringe) [webpage on the Internet]. Leatherhead, UK: Datapharm [updated May 2013]. Available from: http://www.medicines.org.uk/emc/medicine/27216/ SPC/. Accessed August 6, 2012.

49. Orencia (abatacept) [prescribing information]. Princeton, NJ: BristolMyers Squibb Company; 2013. Available from: http://packageinserts. bms.com/pi/pi_orencia.pdf. Accessed April 30, 2013.

50. Nash P, Ludivico C, Delaet I, Qi K, Kaine J. Improvements in disease activity and physical function in patients with RA receiving subcutaneous abatacept in the presence or absence of an initial IV loading dose. Ann Rheum Dis. 2011;70(Suppl 3):SAT0287.

51. Nash P, Ludivico C, Delaet I, et al. Efficacy, safety and pharmacokinetics of subcutaneous abatacept in patients with rheumatoid arthritis, with or without an intravenous (IV) loading dose. Arthritis Rheum. 2011;63(Suppl 10):S151.

52. Schiff M, Alten R, Weinblatt M, et al. Weekly subcutaneous abatacept confers comparable onset of treatment response and magnitude of efficacy improvement over 6 months when administered with or without an intravenous abatacept loading dose. Arthritis Rheum. 2012;64(Suppl 10):S1076.

53. Kaine J, Gladstein G, Strusberg I, et al. Evaluation of abatacept administered subcutaneously in adults with active rheumatoid arthritis: impact of withdrawal and reintroduction on immunogenicity, efficacy and safety (phase Iiib ALLOW study). Ann Rheum Dis. 2012;71(1):38-44.

54. Nash P, Nayiager S, Genovese M, et al. Immunogenicity, safety and efficacy of subcutaneous abatacept with or without MTX in patients with rheumatoid arthritis: the Phase III ACCOMPANY study. Arthritis Care Res. Epub 2012.

55. Kinder AJ, Hassell AB, Brand J, Brownfield A, Grove M, Shadforth MF. The treatment of inflammatory arthritis with methotrexate in clinical practice: treatment duration and incidence of adverse drug reactions. Rheumatology (Oxford). 2005;44(1):61-66.
56. Weinblatt ME, Schiff M, Valente R, et al. Head-to-head comparison of subcutaneous abatacept versus adalimumab for rheumatoid arthritis: findings of a phase IIIb, multinational, prospective, randomized study. Arthritis Rheum. 2013;65(1):28-38.

57. Fleischmann R, Weinblatt ME, Schiff MH, Khanna D, Furst D, Maldonado MA. Changes in patient reported outcomes in response to subcutaneous abatacept or adalimumab in rheumatoid arthritis:results from the AMPLE (abatacept versus adalimumab comparison in biologic naive RA subjects with background methotrexate) trial. Arthritis Rheum. 2012;64(Suppl 10):S578.

58. Singh JA, Christensen R, Wells GA, et al. Biologics for rheumatoid arthritis: an overview of Cochrane reviews. Cochrane Database Syst Rev. 2009;(4):CD007848.

59. Singh JA, Wells GA, Christensen R, et al. Adverse effects of biologics: a network meta-analysis and Cochrane overview. Cochrane Database Syst Rev. 2011;(2):CD008794.

60. Harrold LR, Reed G, Curtis JR, et al. Comparative effectiveness of abatacept versus subsequent anti-TNF agents among rheumatoid arthritis patients with previous anti-TNF exposure. Arthritis Rheum. 2011;63(Suppl 10):S1019.

61. Gottenberg J, Ravaud P, Bardin T, et al. Comparative effectiveness of rituximab and abatacept in 1192 patients with rheumatoid arthritis included in the French Society of Rheumatology AIR and ORA registries. Arthritis Rheum. 2011;63(Suppl 10):S438.

62. Williams EL, Edwards CJ. Patient preferences in choosing anti-TNF therapies-R1. Rheumatology (Oxford). 2006;45(12):1575-1576.

63. Chilton F, Collett RA. Treatment choices, preferences and decisionmaking by patients with rheumatoid arthritis. Musculoskeletal Care. 2008;6(1):1-14.

64. Schiff M, Weinblatt ME, Valente R, et al. Head-to-head comparison of subcutaneous abatacept versus adalimumab for rheumatoid arthritis: two-year efficacy and safety findings from AMPLE trial. Ann Rheum Dis. Epub August 20, 2013.

65. Genovese MC, Cobos AC, Leon G, et al. Subcutaneous (SC) abatacept (ABA) versus intravenous (IV) ABA in patients (pts) with rheumatoid arthritis: long-term data from the ACQUIRE (Abatacept Comparison of sub[QU]cutaneous versus intravenous in Inadequate Responders to methotrexatE) trial. Arthritis Rheum. 2011;63(Suppl 10):S150.
Biologics: Targets \& Therapy

\section{Publish your work in this journal}

Biologics: Targets \& Therapy is an international, peer-reviewed journal focusing on the patho-physiological rationale for and clinical application of Biologic agents in the management of autoimmune diseases, cancers or other pathologies where a molecular target can be identified. This journal is indexed on PubMed Central, CAS, EMBase, Scopus

\section{Dovepress}

and the Elsevier Bibliographic databases. The manuscript management system is completely online and includes a very quick and fair peerreview system, which is all easy to use. Visit http://www.dovepress. com/testimonials.php to read real quotes from published authors. 